\title{
INNOVATIONS IN MEDICAL EDUCATION
}

\section{Adding New Tools to the Black Bag-Introduction of Ultrasound into the Physical Diagnosis Course}

\author{
Nelia Afonso, $M D^{1,3}$, David Amponsah, MD, $R D C S^{2}$, James Yang, $P h D^{2}$, Jennifer Mendez, $P h D^{7}$, \\ Patrick Bridge, $P h D^{7}$, Gregory Hays, $M D^{2}$, sudhir Baliga, $M D^{2}$, Karen Crist, $M A^{7}$, \\ Simone Brennan, $M A^{7}$, Matt Jackson, $P h D^{7}$, and Scott Dulchavsky, MD, PhD ${ }^{2}$ \\ ${ }^{1}$ Wayne State University School of Medicine, Detroit, Michigan; ${ }^{2}$ Henry Ford Hospital, Detroit, Michigan; ${ }^{3}$ Department of Internal Medicine $5 C$ - \\ WSU Health Center, Detroit, MI, USA
}

INTRODUCTION: Ultrasound, a versatile diagnostic modality that permits real-time visualization at the patient's bedside, can be used as an adjunct in teaching physical diagnosis (PD). Aims: (1) to study the feasibility of incorporating ultrasound into PD courses and (2) determine whether learners can demonstrate image recognition and acquisition skills.

PROGRAM DESCRIPTION: Three hundred seven second-year medical students were introduced to cardiovascular and abdominal ultrasound scanning after training in the physical examination. This consisted of a demonstration of the ultrasound examination, followed by practice on standardized patients (SPs). Prepost tests were administered to evaluate students' knowledge and understanding of ultrasound. Students performed an ultrasound examination during the PD final examination.

PROGRAM EVALUATION: Pre-post test data revealed significant improvements in image recognition. On the final exam, the highest scores (98.4\%) were obtained for the internal jugular vein and lowest scores $(74.6 \%)$ on the Focused Assessment with Sonography for Trauma images. Eighty-nine percent of students' surveyed felt ultrasound was a valuable tool for physicians.

DISCUSSION: An introductory ultrasound course is effective in improving medical students' acquisition and recognition of basic cardiovascular and abdominal ultrasound images. This innovative program demonstrates the feasibility of incorporating portable ultrasound as a learning tool during medical school.

KEY WORDS: ultrasound; medical education; physical diagnosis.

J Gen Intern Med 25(11):1248-52

DOI: $10.1007 / \mathrm{s} 11606-010-1451-5$

(C) Society of General Internal Medicine 2010

Electronic supplementary material The online version of this article (doi:10.1007/s11606-010-1451-5) contains supplementary material, which is available to authorized users.

Received March 9, 2010

Revised May 28, 2010

Accepted June 30, 2010

Published online August 10, 2010

\section{INTRODUCTION}

The evolving nature of clinical medicine has placed an increasing demand on the skills required by graduating physicians. It is therefore important to incorporate innovative and clinically useful modalities in order to augment the physician's diagnostic capabilities. For the last couple of centuries the only tools routinely used at the bedside have been the stethoscope, reflex hammer, otoscope and ophthalmoscope. Of all the newer tools, only ultrasound fulfills the criteria of being a versatile and unique diagnostic modality that permits real-time bedside visualization of anatomic and pathologic structures. Hand-held ultrasound devices have been shown to significantly improve the physician's ability to detect a variety of disease states compared to the physical examination alone. ${ }^{1-4}$ Although the use of ultrasound by clinicians is expanding, formal exposure to this technique during medical school is limited.

Wayne State University School of Medicine (WSU-SOM) is one of the first medical schools in the United States to integrate an ultrasound curriculum into both basic science courses and clinical clerkships. ${ }^{5}$ This manuscript describes the WSU-SOM experience of integrating the use of ultrasound into the PD course during the second year of medical school. The aims of this study were to: (1) study the feasibility of teaching ultrasound to medical students during the PD course and (2) to determine whether learners with basic training in ultrasound techniques followed by bedside ultrasound instruction can demonstrate skills in image recognition and acquisition at the end of the course.

\section{Setting}

First year WSU-SOM students are provided an ultrasound curriculum consisting of six organ-system sessions focusing on basic ultrasound physics, study of the knobs (knobology), as well as basic image acquisition skills in abdominal, musculoskeletal, cardiovascular and genitourinary ultrasound imaging. Understanding the relative anatomic relationships of structures is emphasized in the first year curriculum. In order to increase the students' familiarity with the use of ultrasound, and to highlight its diagnostic capabilities, we integrated ultrasound teaching into the second year physical diagnosis (PD) course. We decided to limit the instruction to cardiovascular and abdominal ultrasound since this was our first attempt at incorporating ultrasound into the PD course. The emphasis was on improving image acquisition skills and 
Table 1. Comparison of Student Pre-Test and Post-Test Performance

\begin{tabular}{|c|c|c|c|}
\hline & \multicolumn{3}{|c|}{ Scores and percent correct } \\
\hline & $\begin{array}{l}\text { Pre-test } \\
(n=10)\end{array}$ & $\begin{array}{l}\text { Post- test } \\
(n=10)\end{array}$ & $p$ value* \\
\hline Transducer selection & $35.8(38 \%)$ & 64.2 (68\%) & $<0.001$ \\
\hline $\begin{array}{l}\text { Transducer orientation } \\
\text { Image recognition }\end{array}$ & $26.7(28 \%)$ & 73.3 (75\%) & $<0.001$ \\
\hline $\begin{array}{l}\text { Bladder, short axis } \\
\text { suprapubic view }\end{array}$ & $47.8(87 \%)$ & 52.2 (95\%) & 0.290 \\
\hline $\begin{array}{l}\text { Diaphragm, } \\
\text { perihepatic view (FAST)** }\end{array}$ & 44.7 (76\%) & $55.2(94 \%)$ & 0.100 \\
\hline $\begin{array}{l}\text { Right kidney, } \\
\text { perihepatic view (FAST )** }\end{array}$ & $37.9(58 \%)$ & $62.1(94 \%)$ & $<0.001$ \\
\hline $\begin{array}{l}\text { Gallbladder, } \\
\text { short axis subcostal view }\end{array}$ & $25.3(13 \%)$ & 74.7 (38\%) & $<0.001$ \\
\hline $\begin{array}{l}\text { Cardiovascular, } \\
\text { parasternal long axis } \\
\text { view (PLAX) }\end{array}$ & $40.2(55 \%)$ & $59.7(82 \%)$ & $<0.001$ \\
\hline $\begin{array}{l}\text { Abdominal aorta, } \\
\text { short axis view }\end{array}$ & $34.5(42 \%)$ & $65.5(80 \%)$ & $<0.001$ \\
\hline Left atrium, PLAX & $22.8(22 \%)$ & $77.2(75 \%)$ & $<0.001$ \\
\hline $\begin{array}{l}\text { Internal jugular vein, } \\
\text { short axis view }\end{array}$ & $40.9(32 \%)$ & $59.1(46 \%)$ & $<0.001$ \\
\hline
\end{tabular}

identification of anatomic structures with the clinical applications of a focused bedside ultrasound examination.

\section{PROGRAM DESCRIPTION}

We integrated an anatomic ultrasound curriculum into an existing physical diagnosis course for 307 second year medical students at the WSU-SOM in the academic year 2008-2009. The WSU-SOM Institutional Review Board approved this study. Students could opt out of the study, but were required to participate in the ultrasound sessions as a requirement for the PD course.

\section{Ultrasound Curriculum}

A 3-h ultrasound review session was held for the entire class prior to the introduction of this curriculum. Material taught during the first year was reviewed. Ultrasound sessions were introduced into the PD course after completion of training in basic physical diagnosis techniques. During each 2 -h bedside session, four groups of eight to ten students were assigned to a standardized patient (SP) and a Logic E ultrasound system. Students took turns in demonstrating their image acquisition skills of the cardiovascular and abdominal systems. Examinations were based on a previously developed ultrasound scanning protocol (see online Appendix). Students were also trained to improve image resolution using focal zone adjustment, depth and gain controls. Faculty physicians and residents who had previous ultrasound experience were selected as preceptors and underwent a 3$\mathrm{h}$ training session. This included a detailed review of the scanning protocols and a review of ultrasound images with normal and abnormal findings.
Following the practice session on SPs, the groups met for debriefing with the preceptor. During the debriefing sessions, the students could clarify any uncertainties they had about the ultrasound procedures. Subsequently, representative cases with relevant history and physical examination findings were presented, and students were asked to develop a problem list and differential diagnosis for each case. They were provided the laboratory findings together with illustrative static and dynamic (video) ultrasound images relevant to these cases. Case scenarios were designed to encompass common medical problems related to the cardiovascular and abdominal systems, and to complement the material in the pathophysiology course that was taught concurrently. Emphasis was placed on the interpretation of ultrasound abnormalities in the cases presented. Cardiovascular cases discussed during debriefing included heart failure because of systolic dysfunction, aortic and mitral insufficiency resulting from endocarditis and pericardial effusion with tamponade. The abdominal cases emphasized gallbladder disease (cholelithiasis, acute and chronic cholecystitis), abdominal aortic aneurysm and evaluation of hemoperitoneum resulting from blunt trauma.

Ultrasound Systems. Twenty-six portable Logic E ultrasound systems donated by General Electric (GE) were used to for this study.

\section{Assessments}

Pre-Post-Test Assessment. Prior to the first PD session, a tenitem pre-test was administered to assess the prerequisite knowledge of study participants in the basic cardiovascular and abdominal ultrasound. The students took a post-test after completing both sessions.

Final Examination. One month after the course was completed, further assessment of basic ultrasound skills was performed during the PD Objective Structured Clinical Examination (OSCE). After completion of the history and physical examination, each student was randomly assigned to one of four ultrasound examination stations to obtain a specified image on a SP. Students were given a total of $15 \mathrm{~min}$ to perform an

Table 2. Scores of 4 or 5 per Ultrasound Exam Based on the 5-Point Scoring Criteria (Percentage of Students per Exam Score Category)

\begin{tabular}{lllll}
\hline \hline $\begin{array}{l}\text { Exam } \\
\text { category }\end{array}$ & $\begin{array}{l}\text { Total no. of } \\
\text { students per } \\
\text { exam category }\end{array}$ & Score 4 & Score 5 & Total \\
\hline AA & 75 & $47(62.7 \%)$ & $14(18.7 \%)$ & $61(81.4 \%)$ \\
IJ & 75 & $14(18.7 \%)$ & $59(79.7 \%)$ & $73(98.4 \%)$ \\
LA & 78 & $18(31.6 \%)$ & $41(43.0 \%)$ & $59(74.6 \%)$ \\
FAST & 79 & $25(23.1 \%)$ & $34(18.1 \%)$ & $59(75.2 \%)$ \\
\hline
\end{tabular}

$A A=$ abdominal aorta; $L A=$ subxiphoid cardiac (left atrium); $I J=$ internal jugular vein; FAST = Focused Assessment with Sonography for Trauma (perihepatic view, right kidney) 
Table 3. Final Examination Results: Pair-Wise Comparisons of Student Performance on Ultrasound Evaluation of Abdominal Aorta (AA), Internal Jugular Vein (IJ) and Perihepatic View (FAST)

Number of correct scores per score category

\begin{tabular}{|c|c|c|c|c|c|c|c|c|c|}
\hline Scoring criteria & AA & IJ & p-value & IJ & FAST & $p$-value & AA & FAST & p-value* \\
\hline Orientation & $96 \%$ & $96 \%$ & 1.00 & $96 \%$ & $94 \%$ & 0.515 & $96 \%$ & $94 \%$ & 0.515 \\
\hline Correct image & $96 \%$ & $100 \%$ & 0.082 & $100 \%$ & $86 \%$ & 0.000 & $96 \%$ & $86 \%$ & 0.323 \\
\hline Depth/focal zone & $41 \%$ & $99 \%$ & $<0.000$ & $99 \%$ & $67 \%$ & 0.001 & $41 \%$ & $67 \%$ & $<0.00$ \\
\hline Correct label & $77 \%$ & $92 \%$ & 0.021 & $92 \%$ & $76 \%$ & 0.006 & $77 \%$ & $76 \%$ & 0.687 \\
\hline Image resolution & $73 \%$ & $89 \%$ & 0.011 & $89 \%$ & $53 \%$ & $<0.000$ & $73 \%$ & $53 \%$ & 0.009 \\
\hline
\end{tabular}

$I J$ = internal jugular vein; AA = abdominal aorta; FAST = Focused Assessment with Sonography for Trauma (perihepatic view, right kidney)

*p value derived from weighted Kappa

ultrasound examination of one of the following: internal jugular vein (IJ), abdominal aorta (AA), subxiphoid cardiovascular view or perihepatic view of the Focused Assessment with Sonography for Trauma (FAST) examination. Students had to prepare for all the ultrasound examinations since these were randomly assigned. A completed examination required obtaining a specified image, selecting the best image, labeling a required structure, entering the student's name and saving the final image to the hard drive. Images were scored individually for correct transducer orientation, labeling the correct structure, proper depth/focal zone adjustment, correct label and overall image resolution. Each category was assigned a score of 0 or 1 , for a total score of 5 . As part of training for rating 15, random images per exam category were independently scored by two preceptors to determine inter-rater reliability (IRR). In areas with low IRR, further discussions helped the physicians clarify grading issues and come to a common understanding.

Satisfaction Survey. At the end of the course, the students completed a 14-item survey that assessed their comfort levels and perceptions regarding the diagnostic capabilities of ultrasound.

\section{Data Analyses}

A chi-square test was used to determine the proportions of correct answers between the pre-test and post-test. A post hoc pair-wise analysis of the four final exam images (IJ, cardiac, AA and FAST) was done to determine which cells produced statistically significant differences. Bonferroni correction was used to control the familywise type I error rate for multiple comparisions. An adjusted $\mathrm{p}<0.05$ was used to determine significance.

\section{PROGRAM EVALUATION}

\section{Pre-Post Test Assessment}

There were significant improvements in the post-test areas related to transducer selection and orientation (Table 1). Image recognition of the kidney, gallbladder, cardiac (parasternal long axis view), AA and IJ also improved significantly. The most easily recognized structures were the diaphragm and urinary bladder, with no significant differences in the scores. On the pre-test, students had the most difficulty in recognizing images of the gallbladder and left atrium (LA).

\section{Final Examination Results}

Scores of 4 or 5 out of a possible cumulative score of 5 were obtained on imaging of the right IJ image by $98.4 \%$ of the students in the group, as compared to $81.4 \%, 74.6 \%$ and $75.2 \%$ for the mid-AA in short axis, cardiac view and FAST examinations, respectively (see Table 2). Most students could not correctly identify the gallbladder or the internal jugular vein on the pre- or post-tests, with the majority mistaking both

Table 4. Final Examination Results: Pair-Wise Comparisons of Student Performance on Ultrasound Evaluation of Left Atrium (LA), Internal Jugular Vein (IJ) and Perihepatic View (FAST)

\begin{tabular}{|c|c|c|c|c|c|c|c|c|c|}
\hline \multicolumn{10}{|c|}{ Number of correct scores per score category } \\
\hline Scoring criteria & LA & IJ & $p$-value & LA & AA & $p$-value & LA & FAST & p-value* \\
\hline Orientation & $86 \%$ & $96 \%$ & 0.030 & $86 \%$ & $94 \%$ & 0.030 & $86 \%$ & $94 \%$ & 0.107 \\
\hline Correct image & $92 \%$ & $100 \%$ & 0.014 & $92 \%$ & $86 \%$ & 0.331 & $92 \%$ & $86 \%$ & 0.209 \\
\hline Depth/focal zone & $82 \%$ & $99 \%$ & 0.000 & $82 \%$ & $67 \%$ & $<0.000$ & $82 \%$ & $67 \%$ & 0.804 \\
\hline Correct label & $65 \%$ & $92 \%$ & $<0.000$ & $65 \%$ & $76 \%$ & 0.067 & $65 \%$ & $76 \%$ & 0.145 \\
\hline Image resolution & $74 \%$ & $89 \%$ & 0.016 & $74 \%$ & $53 \%$ & 0.885 & $74 \%$ & $53 \%$ & 0.005 \\
\hline
\end{tabular}

$L A=$ subxiphoid cardiac (left atrium); IJ = internal jugular vein; AA = abdominal aorta; FAST = Focused Assessment with Sonography for Trauma (perihepatic view, right kidney)

*p value derived from weighted Kappa 
structures for the abdominal aorta and the external jugular vein. However, they demonstrated little difficulty imaging both structures (AA, IJ) during the hands-on portion of the final examination. Pair-wise comparisons of the representative images obtained from the four ultrasound examinations resulted in a total of six comparisons, to determine any significant differences in student performance among the various examinations (Tables 3 and 4). Overall, 86\% or more of the students obtained the required images using the proper transducer orientation. The students had the least difficulty in imaging the internal jugular vein (98.4\%), followed by the AA $(81.4 \%)$. There was no significant difference in the FAST and cardiac imaging, which they found more technically challenging.

\section{Student Satisfaction Survey Results}

Eighty-four percent rated the educational value of the ultrasound course ranging from good to excellent. Use of ultrasound was reported to be an important part of the PD course by $78 \%$ of students. The teaching of the cardiovascular and abdominal ultrasound was rated to be effective by $66 \%$ and $70 \%$, respectively. The knowledge and skills in performing ultrasound improved for $89 \%$ of students. Eighty-five percent of students stated that ultrasound was a valuable tool that they would use in their medical practice as primary care physicians or subspecialists.

\section{DISCUSSION}

We demonstrate the practicality of teaching medical students the use of portable ultrasound during the PD course, similar to the use of the stethoscope, ophthalmoscope and otoscope-traditional instruments in a physician's black bag. Incorporation of ultrasound training during the PD course reinforced the concept that ultrasound is an extension of the skills and tools available at the bedside and can be routinely used to improve the accuracy of the physical examination. At the end of the course, students showed a significant improvement in image recognition and acquisition skills as noted in their post-test scores. This improvement may be due to the structured implementation of the longitudinal ultrasound curriculum, consisting of the first year introductory sessions, followed by incorporation into the PD course with emphasis on clinical applications and enhanced scanning opportunities.

A few medical schools have performed pilot projects teaching ultrasound to smaller groups of students with class sizes ranging from 5-176 students. ${ }^{6-14}$ Unlike our project, most of these schools limited ultrasound teaching to senior medical students. ${ }^{7-10}$ Two medical schools that taught ultrasound early in the medical school curriculum restricted it to anatomy courses without bedside clinical applications. ${ }^{9,11}$ However, this study demonstrates the feasibility and acceptability of ultrasound use among second year students in an integrated physical diagnosis course.

Our study has several limitations. The results reflect only our medical school's experience with the incorporation of ultrasound into the medical curriculum. Although this curriculum allowed us to improve upon the basic ultrasound skills taught to our first year medical students, we did not address whether ultrasound teaching improves competence in the physical examination. In addition, this study only assessed students' techniques in performing the ultrasound examination, but did not assess their ability to detect abnormalities. However, before assessing the students' analytic capabilities with a diagnostic tool, they need to be comfortable and competent using this tool. Logical next steps would be an assessment of the improvement of diagnostic skills with practice, as well as retention of these skills as these students progress through medical school. Although we introduced students to only two ultrasound examinations, several other areas, such as musculoskeletal, vascular and obstetric ultrasound, lend themselves to incorporation into the PD course.

Although the full value of bedside US training is yet to be determined, clear benefits are noted. Students are excited about being able to correlate their findings on history and physical examination with real-time imaging of anatomic structures during US examination. We report successful implementation of a novel curriculum to enhance students' knowledge and skills in the use of ultrasound as a part of the physical examination. We hope that the continued use of bedside ultrasound medical school training will facilitate the integration of this technology in routine clinical assessment and facilitate a better understanding of the clinical presentation.

Acknowledgments: Through a partnership with WSUSOM, Henry Ford Health System (HFHS) and General Electric Healthcare, 26 GE Logic E Portable ultrasound machines were donated to the School of Medicine. We would like to thank J. Peiffer, K. Canova, S. McGilvray and G. Nichols from GE Medical for their technical assistance in support of this program.

The authors wish to thank the following people, without whom this would not have been possible:

Dean R. Frank, MD, T. Roe, MD, S. Nelson, C.Ruff, A. Brackney, MD, M. Hafez, MD, M. Sullivan, MD, T. Kirkpatrick, MD, J. ReifelSaltzberg, MD, E. Brauer, MD, S. Abbas, MD, D. Moore II, MD, and P. Gilchrist.

\section{Conflicts of Interest: None disclosed.}

Corresponding Author: Nelia Afonso, MD; Department of Internal Medicine 5C-WSU Health Center, 4201 St Antoine, Detroit, MI 482012153, USA (e-mail: nafonso@med.wayne.edu).

\section{REFERENCES}

1. Kimura BJ, Fowler SJ, Nguyen DT, Amundson SA, DeMaria AN. Detection of early carotid arterial atherosclerosis by briefly trained physicians using a hand-held US device. Am J Cardiol. 2003;92 (2):239-40.

2. Kobal SL, Trento L, Baharami S, et al. Comparison of effectiveness of hand-carried US to bedside cardiovascular physical examination. Am J Cardiol. 2005;96(7):1002-6.

3. Kimura BJ, Shaw DJ, Agan DL, Amundson SA, Ping AC, DeMaria AN. Value of a cardiovascular limited US examination using a hand-carried US device on clinical management in an outpatient medical clinic. Am J Cardiol. 2007;100(2):321-5.

4. Alpert JS, Mladenovic J, Hellmann DB. Should a hand-carried US machine become standard equipment for every internist? Am J Med. 2009; 122(1): 1-3.

5. Rao S, van Holsbeeck L, Musial JL, et al. A pilot study of comprehensive US education at the Wayne State University School of Medicine: a pioneer year review. J US Med. 2008;27(5):745-9. 
6. Shapiro RS, Ko PP, Jacobson S. A pilot project to study the use of ultrasonography for teaching physical examination to medical students. Comput Biol Med. 2002;32(6):403-9.

7. Angtuaco TL, Hopkins RH, DuBose TJ, Bursac Z, Angtuaco MJ, Ferris EJ. Sonographic physical diagnosis 101: teaching senior medical students basic US scanning skills using a compact US system. US Q. 2007;23(2): 157-60

8. Arger PH, Schultz SM, Sehgal CM, Cary TW, Aronchick J. Teaching medical students diagnostic sonography. J US Med. 2005;24 (10): 1365-9.

9. Wittich CM, Montgomery SC, Neben MA, et al. Teaching cardiovascular anatomy to medical students by using a handheld US device. Jama. 2002;288(9):1062-3.

10. Decara JM, Kirkpatrick JN, Spencer KT, et al. Use of hand-carried US devices to augment the accuracy of medical student bedside cardiovascular diagnoses. J Am Soc Echocardiogr. 2005;18(3):25763.

11. Butter J, Grant TH, Egan M, et al. Does US training boost Year 1 medical student competence and confidence when learning abdominal examination? Med Educ. 2007;41(9):843-8.

12. Syperda VA, Trivedi PN, Melo LC, Freeman ML, Ledermann EJ, Smith TM, Alben JO. Ultrasonography in preclinical education: a pilot study. J Am Osteopath Assoc. 2008;108(10):601-5.

13. Fernández-Frackelton M, Peterson M, Lewis RJ, Pérez JE, Coates WC. A bedside ultrasound curriculum for medical students: prospective evaluation of skill acquisition. Teach Learn Med. 2007;19 (1): 14-9.

14. Yoo MC, Villegas L, Jones DB. Basic ultrasound curriculum for medical students: validation of content and phantom. J Laparoendosc Adv Surg Tech A. 2004;14(6):374-9. 